\title{
ГАРАНТИЯ ВОЗВРАТА КРЕДИТА: К ВОПРОСУ О КОЛЛЕКТОРСКОЙ ДЕЯТЕЛЬНОСТИ
}

\begin{abstract}
АНнотАция. В статье рассматривается правовое регулирование коллекторской деятельности в Российской Федерации. Проводится сравнительное исследование существующей нормативно-правовой базы по данному вопросу и на основании этого определяется правовой статус коллекторских агентств в России. Отдельные положения статьи определяют правила и формы взаимодействия кредитных организаций и коллекторских агентств (к ним можно отнести коллекторский аутсорсинг, создание дочернего агентства и, непосредственно, саму продажу задолженности). Сотрудничество между банками и коллекторскими агентствами возможно на основании заключения агентского договора, договора об оказании услуг или договора цессии. Выявляются правовые проблемы, возникающие при передаче кредитором уступки права (требования) третьим лицам. В первую очередь, это правомерность заключения самой цессии, а также передача кредитной организацией коллекторским агентствам сведений, составляющие банковскую тайну. В заключение делается вывод о необходимости более детального правового регулирования коллекторских агентств в Российской Федерации и скорейшем принятии нормативно-правового акта, закрепляющего основные правила, касающиеся правосубъектности коллекторской деятельности.

кЛючЕВЫЕ слОВА. Кредитная организация; коллекторские агентства; заемщик; кредитор; банк; должник; коллекторская деятельность.

ИНФОРМАЦИЯ О СТАТЬЕ. Дата поступления 8 апреля 2016 г.; дата принятия к печати 25 апреля 2016 г.; дата онлайн-размещения 31 мая 2016 г.
\end{abstract}

M. A. Osipova

Baikal State University,

Irkutsk, Russian Federation

\section{GUARANTEE OF REIMBURSEMENT OF CREDIT: ON ISSUE OF DEBT COLLECTION}

\begin{abstract}
The article considers legal regulation of debt collection in the Russian Federation. It carries out a comparative research of the existing standard and legal base in terms of this issue and specifiers the legal status of debt collection agencies in Russia. In its separate provisions the article identifies the rules and forms of interaction of credit institutions and debt collection agencies (with collection outsourcing, creation of affiliated agency and, directly, sale of debts itself to be possibly referred to). Cooperation between banks and debt collection agencies is made possible on the basis of concluding an agency contract, a contract on rendering services or an assignment agreements. The article points out the legal problems arising from the creditor's transferring a concession of the right (demand) to the third parties. First of all, it is the legitimacy of concluding the cession itself, and also the credit organization's transferring the data containing the bank secrecy to collection agencies, Finally, a conclusion is made about the necessity of more detailed legal regulation of debt collection agencies' activities in the Russian Federation, and the fastest adoption of a normative legal act fixing the basic rules concerning the legal identity of debt collection.
\end{abstract}

KEYWORDS. Credit institution; debt collection agencies; borrower; creditor; bank; debtor; debt collection.

ARTICLE INFO. Received April 8, 2016; accepted April 25, 2016; available online May $31,2016$.

\section{Baikal Research Journal}


Современное состояние нормативно-правовой системы Российской Федерации на сегодняшний день не отличается стабильностью и устойчивостью. В российской системе права сложно определить отрасль, которая бы не нуждалась в законодательном совершенствовании. Исключением в данном случае не стала и сфера банковской деятельности [1, с. 161].

В настоящее время в Российской Федерации кредиты стали неотъемлемой частью граждан. Каждый второй россиянин имеет хотя бы один кредит [2, с. 63]. По состоянию на 1 марта 2016 г. выдано более 270 тыс. ипотечных кредитов на общую сумму 485 млрд р. По словам министра строительства и жилищно-коммунального хозяйства М. Меня, в федеральном бюджете на нынешний год предусмотрено 16,5 млрд р., которые пойдут на покрытие обязательств по ранее выданным кредитам и выдачу новых ${ }^{1}$.

По статистике за последние годы количество непогашенных кредитов возросло в несколько раз. Так, подводя итоги за 2014 г., можно констатировать следующие факты: размер непогашенных кредитов и кредитов с просрочкой платежей более чем на три месяца составил 865 млн р., а это почти 8 \% портфеля всех кредитов физических лиц. В 2015 г. просроченные кредиты составляли уже более $17 \%$. Из чего следует неутешительный вывод, что количество кредитов растет и вместе с этим рекордными темпами увеличивается задолженность по кредитам [3, с. 75-94].

Возникает разумный вопрос, как поступать банкам в данной ситуации со своими недобросовестными клиентами. Сразу хотелось бы оговориться, что не все клиенты с просроченными кредитами являются «злостными неплательщиками», часть из них не отказываются платить по кредиту, но на данный момент они не имеют такой возможности, по причине непредвиденных жизненных обстоятельств, например, увольнения с работы, болезни и т. д. Правда, в последнее время всему виной является экономический кризис, коснувшийся не только России, но и всего мирового сообщества.

В сложившейся ситуации у банков есть два варианта работы с непогашенной задолженностью: они могут решать эту проблему своими силами, а могут прибегнуть к помощи сторонних организаций. Не следует забывать также, что банки могут просто продать третьим лицам «просроченную задолженность». Наиболее распространенным методом, направленным на возврат непогашенных кредитных средств, является самостоятельная работа банка со своими клиентами. Однако необходимо отметить, что такая работа осуществляется банками только на ранних стадиях возникновения задолженности, как правило, до 180 дней. Далее проводить ее нецелесообразно, так как для этого требуются определенные затраты, например, самостоятельное осуществление реализации предмета залога или компенсация судебных и иных издержек, связанных с процедурой взыскания задолженности. Большинство банков, понимая неэффективность такой работы, предпочитают сразу прибегнуть к помощи сторонних организаций. Этими организациями чаще всего становятся коллекторские агентства [4, с. 29].

Взаимная работа банков с коллекторскими агентствами может быть реализована в трех направлениях. Во-первых, это создание дочернего агентства (аффилированного с банком-кредитором), во-вторых, это коллекторский аутсорсинг, т. е. передача кредиторской задолженности для ее взыскания коллекторским агентствам на условиях комиссии, и, в-третьих, это продажа задолженности сторонним коллекторским агентствам [5, с. 23].

На практике наиболее предпочтительными являются второе и третье направления, что же касается создания дочернего агентства, то следует отметить, лишь немногие банки могут себе это позволить. Однако такой опыт в России все-таки

\footnotetext{
${ }^{1}$ Мень: Господдержка ипотеки поможет рынку жилья [Электронный ресурс] // Новости банковского сектора. URL : http://www.vestifi№a№ce.ru/articles/69237.
}

\section{Baikal Research Journal}


имеется. ООО «Сентинел Кредит Менеджмент» - первое коллекторское агентство, предоставляющее услуги полного цикла взыскания просроченной задолженности, включая внесудебное урегулирование силами дистанционного и выездного взыскания, а также организацию и сопровождение взыскания в рамках судебного и исполнительного производств. Оно возникло в результате преобразования в 2011 г. дирекции по взысканию просроченной задолженности ОАО «Альфа-Банк». В настоящее время компания осуществляет процесс взыскания на любой стадии просроченной задолженности и имеет обширную региональную сеть (более 40 подразделений и 72 точек присутствия) [6, с. 36]. В 2013 г. Сбербанк продолжил уже начатую традицию и создал свое коллекторское агентство «Активбизнесколлекшн», которое специализируется на взыскании долгов по кредитным картам и потребительским кредитам. Несмотря на создание собственной коллекторской компании, Сбербанк продолжает взаимодействовать с иными коллекторскими агентствами по продаже непогашенных кредитов [7, с. 34].

Коллекторские агентства при работе с кредитными организациями, как правило, используют следующие формы взаимодействия:

- доверенность;

- агентский договор или договор поручения;

- договор об оказании услуг или о сотрудничестве;

- договор цессии.

Под доверенностью согласно ст. 185 Гражданского кодекса РФ (ГК РФ) понимается письменное уполномочие, выдаваемое одним лицом другому или другим лицам для представительства перед третьими лицами. Совместная работа кредитных организаций и коллекторских агентств предполагает заключение различных видов доверенностей: для лищ, осуществляющих непосредственный контакт с должником на этапе досудебной работы, для представителей в суде, а также в службах судебных приставов и правоохранительных органах. Обязательным условием данной формы взаимодействия является отсутствие права передоверия указанного документа третьим лицам. Обычно доверенность выдается на имя конкретных работников коллекторских агентств, а не на целую организацию. Для успешного применения доверенности в ходе взыскания неплатежа рационально зафиксировать и выделить отдельные пункты, касающиеся прав и обязанностей коллектора. Так, например, в доверенности может быть отмечено, что представитель вправе заключать мировое соглашение, прощать долг частично, в сумме штрафных санкций и т. д. [8, с. 48].

Если рассматривать агентский договор и договор об оказании услуг, то в том и в другом случаях коллекторские агентства действуют по поручению банка, от его имени и в интересах кредитной организации. Обычно в своем содержании договор об оказании услуг предусматривает выплату коллекторам процентов от реально взысканных сумм долгов. В агентском договоре четко определяется общий объем работы агентства, количество долгов, их полная сумма, сроки передачи информации по должнику и т. д. Указанные формы, безусловно, используются кредитными организациями и коллекторскими агентствами, но наиболее распространенной из предложенных является заключение договора цессии [9, с. 40].

Несмотря на популярность такой формы у банков, на практике не сложилось единого мнения относительно ее применения. Это, в первую очередь, связано с правомерностью заключения самой цессии, а точнее с наличием у цессионария специальной правосубъектности для перехода уступки права требования. И, во-вторых, ключевой проблемой при передаче уступки требования является вопрос о неразглашение сведений, составляющих банковскую тайну [10, с. 25].

Цессия (от лат. cessio - передача) уступка, передача другим лицам своего права на обладание собственностью, средствами или права на их получение. При за-

\section{Baikal Research Journal}


ключении договора цессии цедент (прежний кредитор) передает свое право на получение долга цессионарию (третье лицо, новый кредитор) на основании положений, предусмотренных законодательством.

Согласно ст. 382 ГК РФ право (требование), принадлежащее кредитору на основании обязательства, может быть передано им другому лицу по сделке (уступка требования) или перейти к другому лицу на основании закона. Для перехода прав кредитора к другому лицу не требуется согласие должника, если другое не предусмотрено законом или договором.

При заключении договора цессии между банком и коллекторским агентством достаточно спорным моментом является правовое положение коллекторов. Коллекторские агентства не являются кредитными организациями, но выступая в качестве цессионария, автоматически становятся субъектами банковской сферы. Для совершения операций в данной сфере требуется обязательное лицензирование деятельности самой организации. У коллекторских агентств такой лицензии нет.

Достаточно категорично высказал свое мнение по данному вопросу Роспотребнадзор. С его точки зрения, передача банком права требования долга с заемщика коллекторским агентствам не основана на нормах действующего законодательства. Кроме того, при уступке права требования кредитора лицу, не являющемуся кредитной организацией, нарушаются не только частные интересы участников, но и публичные интересы. Такая уступка представляет собой вывод кредитором из собственного оборота части собственных средств, который может привести, во-первых, $\kappa$ невозможности удовлетворения требований вкладчиков и, во-вторых, к снижению показателей обязательных нормативов банка, установленных Банком России ${ }^{2}$.

Относительно данной проблемы судебная практика, напротив, придерживается противоположного мнения. В информационном письме Президиума Высшего Арбитражного Суда РФ было указано, что уступка банком прав кредитора по кредитному договору юридическому лицу, не являющемуся кредитной организацией, не противоречит законодательству. Помимо этого отмечалось: «уступка не относится к числу банковских операций» и «с выдачей кредита лицензируемая деятельность банка считается реализованной» ${ }^{3}$. Из чего можно сделать вывод о том, что наличие лицензии обязательно только для осуществления деятельности по выдаче кредитов за счет привлеченных средств, а с выдачей такого кредита лицензируемая деятельность банка считается реализованной.

В последующих правовых документах Президиум Высшего Арбитражного Суда РФ еще более конкретизировал свою позицию, указав, что уступка банком лицу, не обладающему статусом кредитной организации, не исполненного в срок требования по кредитному договору с заемщиком-гражданином, не противоречит закону и не требует согласия заемщика ${ }^{4}$.

Рассматривая вопрос об информации, составляющую банковскую тайну, необходимо пояснить следующее: при заключении договора цессии банки одновременно предоставляют коллекторским агентствам личные сведения о заемщике. На прак-

${ }^{2}$ Об отдельных аспектах правоприменительной практики по привлечению банков к административной ответственности за нарушение законодательства о защите прав потребителей [Электронный ресурс] : письмо Федер. службы по надзору в сфере защиты прав потребителей и благополучия человека от 2 нояб. 2011 г. № 01/13941-1-3 // СПС «КонсультантПлюс».

${ }^{3}$ Обзор практики применения арбитражными судами положений главы 24 Гражданского кодекса Российской Федерации : информ. письмо Президиума Высш. Арбитр. Суда РФ от 30 окт. 2007 г. № 120 // Вестник Высшего Арбитражного Суда Российской Федерации. 2008. № 1.

${ }^{4}$ Обзор судебной практики по некоторым вопросам, связанным с применением к банкам административной ответственности за нарушение законодательства о защите прав потребителей при заключении кредитных договоров : письмо Президиума Высш. Арбитр. Суда РФ от 13 сент. 2011 г. № 146 // Вестник Высшего Арбитражного Суда Российской Федерации. 2011. № 11.

\section{Baikal Research Journal}


тике данные действия кредитной организации вызывают неоднозначную реакцию как со стороны государственных органов, так и со стороны общественности.

В ст. 26 Федерального закона «О банках и банковской деятельности» предусматривается закрытый перечень субъектов, которые обладают исключительным правом доступа к конфиденциальной информации, в данном случае, составляющей банковскую тайну ${ }^{5}$. Коллекторские агентства в этой статье не значатся. Указанная статья также содержит положения об ответственности за разглашение сведений, составляющих банковскую тайну. Если коллекторские агентства не являются субъектами, имеющими право доступа к конфиденциальной информации, соответственно, они не несут ответственность за разглашение такой информации. В этой связи возникает вопрос о правомерности действий банка при заключении договора цессии.

Федеральная служба по надзору в сфере защиты прав потребителей и благополучия человека, отстаивая свою позицию, определяет, что уступка права требования по обязательствам, возникшим между банком и гражданином, третьему лицу (коллекторскому агентству) без нарушения указанных норм права, объективно не возможна [11, с. 32]. Высший Арбитражный Суд РФ поддержал Роспотребнадзор в этом вопросе и в своем определении указал: «право заемщика на сохранение информации об его банковском счете, операций по этому счету, а также сведений, касающихся непосредственно самого заемщика, являются тайной, и разглашение этих сведений третьим лицам, не указанным в законе, нарушает его права» ${ }^{6}$.

В научной литературе можно встретить различные мнения по поводу данной проблемы. Так, С. А. Даниленко полагает, что если мероприятия по взысканию просроченной задолженности проводятся третьим лицом (коллекторами), то упомянутое лицо вправе использовать сведения о заключенной между кредитной организацией и заемщиком сделке по предоставлению кредита в случае сохранения конфиденциальности данных сведений $[12$, с. 97]. В свою очередь, Е. В. Фаткина считает, что действия кредитной организации при заключении договора цессии могут быть рассмотрены как неправомерное раскрытие информации третьим лицам $[13$, с. 99].

Верховный Суд РФ в своем постановлении «О рассмотрении судами гражданских дел по спорам о защите прав потребителей» от 28 июня 2012 г. № 17 обозначил условие, при соблюдении которого действия кредитных организаций по передаче информации коллекторским агентствам будут признаваться законными. Этим условием выступает согласие должника на передачу таких данных ${ }^{7}$

Существующую коллизию частично разрешил вступивший в силу 1 июля 2014 г. Федеральный закон «О потребительском кредите (займе)» ${ }^{8}$ В ст. 12 этого закона закреплено право осуществления уступки требования по договору потребительского кредита третьим лицам, в том числе небанковским организациям. $\mathrm{K}$ ним и будут относиться коллекторские агентства. Кроме этого, в ст. 15 определены формы и способы взаимодействия коллекторских агентств с должниками, а также установлен список недопустимых действий со стороны кредитора и третьих лиц, осуществляющих деятельность по возврату задолженности в отношении должника.

\footnotetext{
${ }^{5}$ О банках и банковской деятельности [Электронный ресурс] : федер. закон от 2 дек.1990 г. № 395-I (ред. от 29 дек. 2015 г.) // СПС «КонсультантПлюс».

${ }^{6}$ Об отказе в передаче дела в президиум высшего арбитражного суда российской федерации [Электронный ресурс] : определение Высшего Арбитражного Суда РФ от 14 июля 2011 г. № ВАС-8679/11 по делу № А37-944/2010 // СПС «КонсультантПлюс» .

${ }^{7}$ О рассмотрении судами гражданских дел по спорам о защите прав потребителей : постановление Пленума Верховного Суда РФ от 28 июня 2012 г. № 17 // Российская газета. 2012. 11 июля.

${ }^{8}$ О потребительском кредите (займе) : федер. закон от 21 дек. 2013 г. № 353-ФЗ // Собрание законодательства Российской Федерации. 2013. № 51. Ст. 6673.
}

\section{Baikal Research Journal}


Принятие данного закона хотя и внесло определенную ясность в регулирование коллекторской деятельности, однако всю полноту проблемы не охватило. Созданных норм недостаточно для полноценного регулирования коллекторской деятельности.

В последнее время все чаще в средствах массовой информации можно встретить негативные высказывания в сторону неправомерных действий коллекторских агентств. Возможно, такое поведение коллекторов послужило своеобразным катализатором для пересмотра существующей нормативно-правовой базы.

Так, Председатель Совета Федерации РФ в начале 2016 г. справедливо отметил, что особого внимания заслуживает ситуация, возникшая в последнее время на рынке коллекторских услуг и требующая на сегодняшний день незамедлительного разрешения. В верхнюю палату Федерального Собрания РФ поступают обращения, большая часть которых связана с взысканием задолженности по кредитным обязательствам, осуществляемым коллекторскими агентствами. Председатель Государственной Думы РФ В. Матвиенко, опасаясь, что нарушение коллекторами прав должников через применение недобросовестных методов воздействия может привести к росту социальной напряженности в стране, поддержала С. Нарышкина. Уже в феврале текущего года в нижнюю палату Федерального Собрания РФ от имени председателей палат парламента был внесен законопроект о коллекторской деятельности.

При этом В. Матвиенко пояснила, что законодатели не отменяли обязанности должников платить по кредитам, а попытались установить баланс интересов кредиторов и заемщиков ${ }^{9}$. Законопроект четко регулирует правила взаимодействия с должником банков, микрофинансовых организаций, других кредиторов и лиц, осуществляющих взыскание задолженности. Его основные положениям помогут ликвидировать угрозы жизни и здоровью должников, избавить их от запугивания и вторжений в жилище, помешать распространению порочащих их сведений, а также предотвратить незаконное использование сведений, составляющих персональные данные.

Одним из наиболее важных пунктов законопроекта является создание специального органа, который будет вести реестр коллекторов, а также осуществлять контроль за их деятельностью. Законопроект должен был рассматриваться на заседании Государственной Думы РФ 25 марта 2016 г., однако был перенесен на апрель месяц. По словам спикера нижней палаты Парламента, это связано с внесением альтернативных законопроектов.

Учитывая пробельность законодательства в области регулирования коллекторской деятельности, хотелось бы надеяться, что данный законопроект будет принят Федеральным Собранием РФ уже в ближайшее время и вступит в законную силу в 2016 г.

\section{Список использованной литературы}

1. Осипова М. А. О понятии банковской деятельности в Российской Федерации / М. А. Осипова // Известия Иркутской государственной экономической академии. - 2012. № $2(82)$. - C. 161-166.

2. Поляков В. В. Доверие как фактор поведения потребителей банковских услуг / В. В. Поляков // Известия Иркутской государственной экономической академии. - 2012. № 5 (85). - C. 61-65.

3. Самаруха В. И. Деньги, кредит, банки / В. И. Самаруха, И. В. Самаруха, А. В. Самаруха. - Иркутск : Изд-во БГУЭП, 2015. - 166 с.

${ }^{9}$ Закон о коллекторской деятельности 2016 г. внесен в ГД [Электронный ресурс] // Уральский союз. URL : http://www.uralsoyuz.ru/news/1623.

\section{Baikal Research Journal}


4. Жданухин Д. Ю. Уголовный кодекс на службе коллекторов / Д. Ю. Ж данухин // ЭЖЖ-Юрист. - 2006. - № 41. - С. 29-31.

5. Казакова Е. Б. Деятельность коллекторских агентств по взысканию просроченной задолженности заемщика перед банком: проблемы правового регулирования / Е. Б. Казакова // Концепт. - 2014. — № S27. - C. 21-25.

6. Сарнаков И. В. Договорное регулирование отношений, возникающих между кредитными организациями и коллекторскими агентствами в процессе возврата кредиторской задолженности / И. В. Сарнаков // Банковское право. - 2015. — № 1. — С. 31-36.

7. Хоменко Е. Г. Работа банков с просроченными потребительскими кредитами / Е. Г. Хоменко // Право и экономика. - 2014. — № 7. - С. 32-36.

8. Жданухин Д. Ю. Полномочия передаем коллектору / Д. Ю. ЖЖданухин, А. В. Федоров // Консультант. - 2007. - № 1. - С. 47-49.

9. Сарнаков И. В. О возможности уступки права требования возврата денежных средств по кредитному договору / И. В. Сарнаков // Банковское право. - 2011. — № 5. - С. 39-42.

10. Фаткина Е. В. Проблемы правового регулирования режима конфиденциальности информации, составляющей банковскую тайну / Е. В. Фаткина // Банковское право. — 2013. — № 4. - С. 23-29.

11. Сарнаков И. В. Правовые формы взаимодействия кредитных организаций и коллекторских агентств на рынке банковских услуг/ И. В. Сарнаков // Юрист. - 2015. - № 2. С. 30-33.

12. Даниленко С. А. Банковское потребительское кредитование / С. А. Даниленко, М. В. Комиссарова. - М. : Юстицинформ, 2011. - 384 с.

13.Фаткина Е. В. Передача долга для взыскания коллектору: проблемы соблюдения банковской тайны / Е. В. Фаткина // Актуальные проблемы российского права. - 2015. № 7 . - С. 95-101.

\section{References}

1. Osipova M. A. On concept of banking activities in the Russian Federation. Izvestiya Irkutskoy gosudarstvennoy ekonomicheskoy akademii = Bulletin of Irkutsk State Economics Academy, 2012, no. 2 (82), pp. 161-166. (In Russian).

2. Polyakov V. V. Confidence as a behavioral factor of banking service consumers. Izvestiya Irkutskoy gosudarstvennoy ekonomicheskoy akademii = Bulletin of Irkutsk State Economics Academy, 2012, no. 5 (85), pp. 61-65. (In Russian)

3. Samarukha V. I., Samarukha I. V., Samarukha A. V. Den'gi, kredit, banki [Money, credit, banks]. Irkutsk, Baikal State University of Economics and Law Publ., 2015. 166 p.

4. Zhdanukhin D. Yu. Criminal code in the service of collectors. EJ-Jurist, 2006, no. 41, pp. 29-31. (In Russian).

5. Kazakova E. B. Activities of debt collection agencies in recovering borrower's overdue bank debts: problems of legal regulation. Kontsept = Concept, 2014, no. S27, pp. 21-25. (In Russian).

6. Sarnakov I. Contractual regulation of relations arising between credit organizations and debt collection agencies in the process of recovering loan debts. Bankovskoe pravo = Banking Law, 2015, no. 1, pp. 31-36. (In Russian).

7. Khomenko E. G. Bank's activities with overdue consumer loans. Pravo i ekonomika $=$ Law and Economics, 2014, no. 7, pp. 32-36. (In Russian).

8. Zhdanukhin D. Yu., Fedorov A. V. Powers are delegated to the collector. Konsul'tant= Consultant, 2007, no. 1, pp. 47-49. (In Russian).

9. Sarnakov I. V. On possibility of cession of rights for demanding refund in term of credit contract. Bankovskoe pravo = Banking Law, 2011, no. 5, pp. 39-42. (In Russian).

10. Fatkina E. V. Legal issues of confidentiality of information constituting bank secrecy. Bankovskoe pravo = Banking Law, 2013, no. 4, pp. 23-29. (In Russian).

11. Sarnakov I. V. Legal forms of interaction of credit organizations and debt collection agencies on the banking service market. Yurist = Lawer, 2015, no. 2, pp. 30-33. (In Russian).

12. Danilenko S. A., Komissarova M. V. Bankovskoe potrebitel'skoe kreditovanie [Bank consumer crediting]. Moscow, Yustitsinform Publ., 2011. 384 p.

13. Fatkina E. V. Transferring debts for recovering debts by the collector: problems of keeping bank secrecy. Aktual'nye problemy rossiiskogo prava = Topical Problems of Russian Law, 2015, no. 7, pp. 95-101. (In Russian).

\section{Baikal Research Journal}




\section{Информация об авторе}

Осипова Марина Анатольевна - доцент, кафедра правового обеспечения национальной безопасности, Байкальский государственный университет, 664003, г. Иркутск, ул. Ленина 11, e-mail: om1979@mail.ru.

\section{Author}

Marina A. Osipova - Associate Professor, Chair of Judicial Support of National Security, Baikal State University, 11 Lenin St., 664003, Irkutsk, Russian Federation; e-mail: om1979@mail.ru.

\section{Библиографическое описание статьи}

Осипова М. А. Гарантия возврата кредита: к вопросу о коллекторской деятельности / M. А. Осипова // Baikal Research Journal. - 2016. — T. 7, № 3. — DOI : 10.17150/24116262.2016.7(3).23.

\section{Reference to article}

Osipova M. A. Guarantee of reimbursement of credit: on issue of debt collection. Baikal Research Journal, 2016, vol. 7, no. 3. DOI: 10.17150/2411-6262.2016.7(3).23. (In Russian).

\section{Baikal Research Journal}

